\title{
Infectious Keratitis
}

National Cancer Institute

\section{Source}

National Cancer Institute. Infectious Keratitis. NCI Thesaurus. Code C118749.

Inflammation of the cornea secondary to an infectious process. 